\title{
Response of electrostatic probes to eccentric charge distributions
}

\author{
Johansson, Torben; McAllister, lain Wilson
}

Published in:

Proceedings on Conference on Electrical Insulation and Dielectric Phenomena

Link to article, DOI:

10.1109/CEIDP.2001.963629

Publication date:

2001

Document Version

Publisher's PDF, also known as Version of record

Link back to DTU Orbit

Citation (APA):

Johansson, T., \& McAllister, I. W. (2001). Response of electrostatic probes to eccentric charge distributions. In Proceedings on Conference on Electrical Insulation and Dielectric Phenomena (pp. 652-655)

https://doi.org/10.1109/CEIDP.2001.963629

\section{General rights}

Copyright and moral rights for the publications made accessible in the public portal are retained by the authors and/or other copyright owners and it is a condition of accessing publications that users recognise and abide by the legal requirements associated with these rights.

- Users may download and print one copy of any publication from the public portal for the purpose of private study or research.

- You may not further distribute the material or use it for any profit-making activity or commercial gain

- You may freely distribute the URL identifying the publication in the public portal

If you believe that this document breaches copyright please contact us providing details, and we will remove access to the work immediately and investigate your claim 


\title{
Response of electrostatic probes to eccentric charge distributions
}

\author{
T. Johansson and I. W. McAllister \\ Department of Electric Power Engineering \\ Technical University of Denmark \\ Lyngby, Denmark
}

\begin{abstract}
The response of an electrostatic probe mounted in an electrode is examined with reference to eccentric charge distributions. The study involves using the probe $\lambda$ function to derive a characteristic parameter. This parameter enables the response of the probe to different degrees of eccentricity to be quantitatively assessed.
\end{abstract}

\section{Introduction}

Bound electrostatic probes are typically employed to study electrical discharge activity along the surface of gas/solid-dielectric interfaces $[1,2]$. The word bound signifies that the probe is mounted in the electrode in contact with the solid dielectric, see Figure 1 [3]. Thus, as the probe is an integral part of this electrode, such probes lack the freedom of movement necessary to implement a scanning procedure which is required for a correct quantitative evaluation of the surface charge to be made $[4,5]$.

In $[1,2]$ the charge was deposited on the dielectric surface by a corona discharge from a point electrode. Thus although the bound probe itself is not free to move, the bounding (plane) electrode may be moved relative to the point electrode. Hence when this electrode and the probe are not coaxially aligned, an eccentric charge situation will arise.

Charges are electrostatically induced on the probe sensor plate by the presence of a source charge. The relationship between the induced charge and this interface source charge is expressible in terms of a general function, the $\lambda$ function [6]. Using this function it is possible to examine the response of electrostatic probes.

In the present study, the response of bound probes to eccentric surface charge distributions is investigated. For a rotationally symmetric surface charge, the eccentricity refers to the fact that the axis of the probe and that of the surface charge are displaced from one other.
The probe responses are examined with reference to

the degree of eccentricity and compared with the associated concentric responses. In this way, the eccentricity of the charge distribution is shown to have a significant effect upon the probe response. For a given $\lambda$ function, this response is controlled by the spatial dimensions of the surface charge.

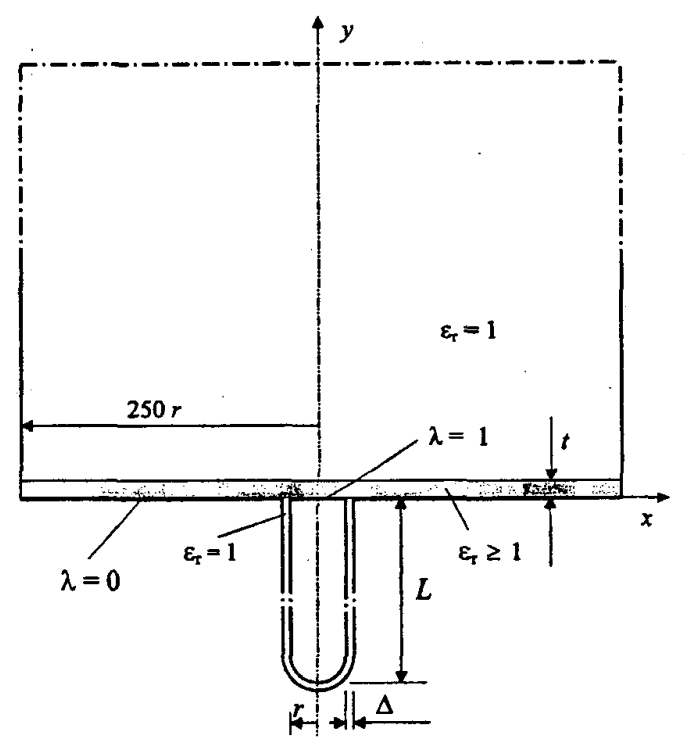

Figure 1: Bound probe geometry.

\section{The $\lambda$ function}

The $\lambda$ function is the proportionality factor between the charge induced on the probe to any charge within the dielectric volume or at an interface [6]. If it is assumed that the volume charge density in the solid dielectric is zero, then this relationship can be expressed simply as 
$q=-\iint_{A_{\mathrm{o}}} \lambda \sigma \mathrm{d} A$

where $q$ is the Poissonian induced charge on the probe sensor plate, and $\sigma$ is the surface charge density on the surface element $d A$ of $A_{0}$, the surface of the solid dielectric.

The dimensionless parameter $\lambda$ is a solution of the general Laplace equation for the complete system geometry:

$$
\vec{\nabla} \bullet(\varepsilon \vec{\nabla} \lambda)=0
$$

The boundary conditions are $\lambda=1$ at the probe sensor plate and $\lambda=0$ at all other electrodes. In addition, at dielectric interfaces the normal derivatives of $\lambda$ must obey the condition

$\varepsilon_{+}\left[\frac{\partial \lambda}{\partial n}\right]_{+}=\varepsilon_{-}\left[\frac{\partial \lambda}{\partial n}\right]_{-}$

where the + and - signs refer to the opposite sides of the interface. As (2) is just Laplace's equation, any standard method of solving this equation can be employed to evaluate the variation of $\lambda$ along the interface. On this occasion, solutions of Laplace's equation were obtained using a finite element software package. These solutions were then used to study the dependence of the probe response upon the surface charge distribution.

\section{Probe/dielectric geometry}

The geometry of the bound probe used in this study is shown in Figure 1, in which $r$ is the radius of the sensor plate and $x$ is the radial distance from the probe axis. The gap between the sensor plate and the remainder of the electrode is $\Delta$. To minimise the influence of the probe length $L$ on $\lambda$, the former parameter is set to $25 r$.

The planar dielectric, of relative permittivity $\varepsilon_{\mathrm{r}}$, has a thickness $t$ in a direction normal to the plane electrode which, along with the probe shield, is grounded. In the direction normal to the probe axis, the extent of the solid-dielectric/plane-electrode is much greater than the probe lateral dimensions. With the present software this distance is made $250 \mathrm{r}$.
As the influence of the probe/dielectric geometry upon the $\lambda$ function for a bound probe is discussed in [3], it is only necessary to illustrate the variation of $\lambda$ along the gas/solid-dielectric interface for the probe geometry employed in the present study, viz. $\Delta / r=0.5$, $\varepsilon_{\mathrm{r}}=4, t / r=0.5$. The relevant $\lambda$ function is shown in Figure 2 .

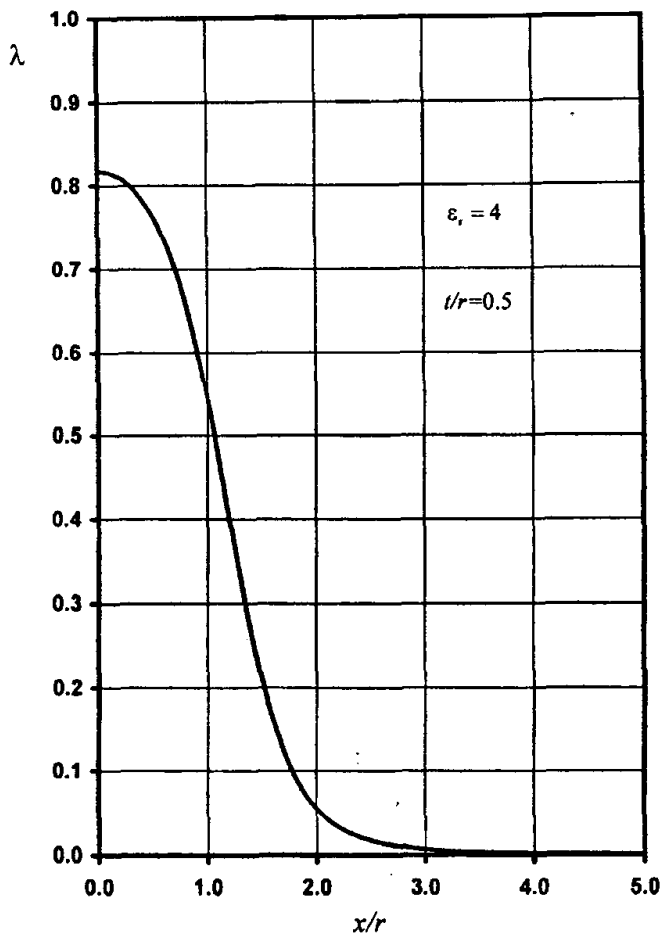

Figure 2: Variation of $\lambda$ along the interface.

\section{Surface charge distributions}

Previous studies have considered the probe axis and the axis of a symmetrical surface charge to be concentric [3,7-11]. However if the probe is moved to another location, then these axes will be eccentric. Such situations may be represented as shown in Figure 3. The surface charge is represented by a circular disc of charge, of radius $b$. On this occasion, the charge density $\sigma$ will be considered uniform, i.e. $\sigma=\sigma_{0}$. The extent of the charge distribution was altered by varying the value of $b$. The $b$ values were selected such that the total charge per disc is in the ratio $1: 2: 5: 10$. This lead to $b / r=2,2 \sqrt{2}, 2 \sqrt{5}, 2 \sqrt{10}$. 
The significance of the eccentricity can be studied by examining the variations in the charge induced on the probe sensor plate. Owing to the lack of $\sigma$ symme-try with respect to the probe, it is only meaningful to discuss the total induced charge $q_{\mathrm{T}}$. A uniform charge density allows (1) to be expressed as

$q_{\mathrm{T}}(s)=-\sigma_{0} \iint_{s} \lambda \mathrm{d} A$

where $s$ represents the probe offset, see Figure 3, while $S$ is the surface charge area.

Traditionally, electrostatic probe measurements are interpreted as though the probe responds only to the charge directly subtended by the sensor plate, i.e. the value of charge $Q$ assumed to be measured is given by

$Q=\pi r^{2} \sigma_{0}$

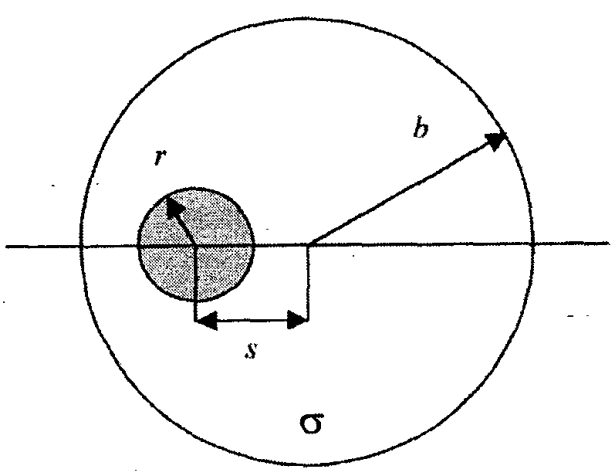

Figure 3: Probe/surface-charge geometry.

By using this charge value as a normalising factor, it is possible to examine the behaviour of the ratio $\left|q_{\mathrm{T}}(0)\right| / Q$, i.e.

$\frac{\left|q_{\mathrm{T}}(0)\right|}{Q}=\frac{1}{\pi r^{2}} \iint_{S} \lambda \mathrm{d} A$

This ratio represents a measure of the probe detection sensitivity. For $s=0$, the charge and the probe axes are collinear, and thus $q_{\mathrm{T}}(0)$ represents the maximum value of the charge induced on the probe by the disc of charge.
The variation of this ratio is shown in Figure 4 . With respect to $Q, q_{\mathrm{T}}(0)$ is seen to increase with $b / r$ to some asymptotic value, which for the present probe is about $1.5 Q$. This implies that, depending on the $b / r$ value, the outer lying areas of charge $(b / r>1)$ can contribute more than $50 \%$ of the probe signal.

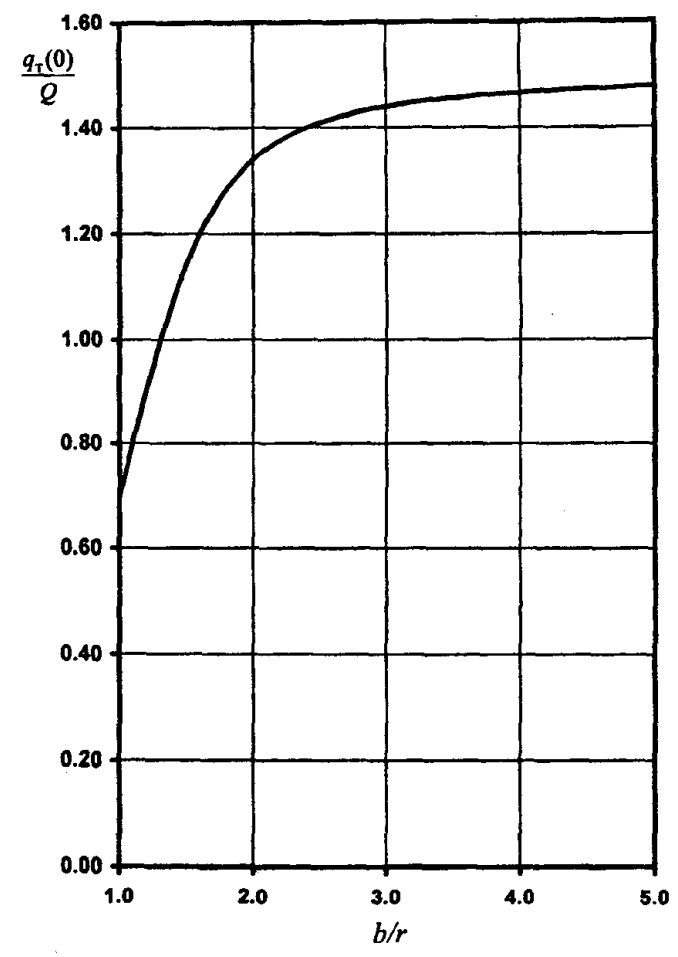

Figure 4: Variation of $q_{\mathrm{T}}(0) / Q$.

The effects of charge eccentricity can be assessed by considering the variation of the ratio $q_{\mathrm{T}}(s) / q_{\mathrm{T}}(0)$. This is illustrated in Figure 5 for several values of $b / r$. As the degree of eccentricity $(s / r)$ increases, the initial rate of decrease of the induced charge is controlled by the relative dimensions of the charged area. Thereafter the induced charge decreases rapidly as the probe traverses the edge of the charge region, e.g. for $(b / r)-1 \leq$ $s / r \leq(b / r)+1$, the value of $q_{\mathrm{T}}(s) / q_{\mathrm{T}}(0)$ falls from about 0.85 to 0.1 . This decrease is essentially independent of the relative disc size, $i . e . b / r$.

For $s / r \geq(b / r)+1$, no charge is directly subtended by the probe sensor. However Figure 4 indicates the probe responds to the non-local areas of charge. This is 
confirmed in Figure 5. However the existence of a probe signal is traditionally taken to imply the presence of charge directly above the sensor plate.

Such an interpretation will lead to the wrong conclusion with respect to the spatial extent of the surface charge. The degree of error associated with this aspect is presently under study.

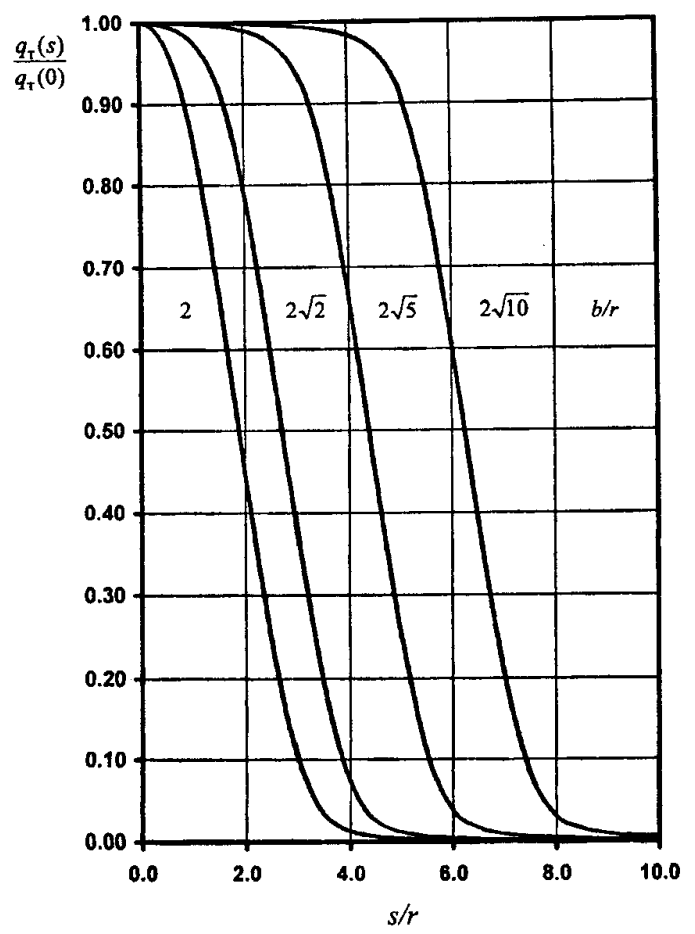

Figure 5: Variation of $q_{\mathrm{T}}(s) / q_{\mathrm{T}}(0)$.

\section{Conclusions}

The response of the probe to eccentric charge distributions is controlled by the spatial dimensions of the surface charge. Nevertheless the response to the transition region from charge to no-charge is essentially independent of these dimensions.

As the probe responds to non-local charge, this characteristic will invariably lead to errors in any assessment of the spatial extent of the surface charge.

\section{Acknowledgment}

The authors wish to acknowledge the assistance of $\mathrm{J}$. Berril in producing this Word document. Without his help this paper could not have been produced in the time available.

\section{References}

[1] M. Endo, N. Noro and T. Sakakibara, "Field strength of surface discharge initiation (II)", XI International Conference on Gas Discharges and Their Applications, Tokyo, pp.II/118II/121, 1995.

[2] M. Endo, N. Harigaya, H. Suzuki and T. Sakakibara, "Field strength of surface discharge initiation (III)", XII International Conference on Gas Discharges and Their Applications, Greifswald, pp.I/260-I/263, 1997.

[3] T. Johansson, G. C. Crichton and I. W. McAllister, "Measurement of surface charge densities associated with surface discharges", XIII International Conference on Gas Discharges and Their Applications, Glasgow, pp.892-895, 2000.

[4] M. Yashima, H. Fujinami and T. Takuma, "Measurement of accumulated charge on dielectric surfaces with an electrostatic probe", in L. G. Christophorou and D. W. Bouldin (eds.), Gaseous Dielectrics V, Pergamon New York, pp.242-247, 1987.

[5] T. O. Rerup, G. C. Crichton and I.W. McAllister, "Using the $\lambda$ function to evaluate probe measurements of charged dielectric surfaces", IEEE Trans. Diel. Elect. Insul., 3, pp.770-777, 1996.

[6] A. Pedersen, "On the electrostatics of probe measurements of surface charge densities", in L. G. Christophouru and D. W. Bouldin (eds.), Gaseous Dielectrics V, Pergamon New York, pp.235-240, 1987.

[7] T. Johansson and I. W. McAllister, "Response of electrostatic probes to non-uniform charge distributions", NORD-IS 01, Stockholm, pp.271-279, 2001.

[8] T. Johansson, G. C. Crichton and I. W. McAllister, "Influence of probe geometry on the response of an electrostatic probe", 1999 Annual Report - Conference on Electrical Insulation and Dielectric Phenomena, IEEE Publication 99CH36319, pp.137141, 1999.

[9] T, O. Rerup, G. C. Crichton and I. W. McAllister, " Response of an electrostatic probe for a right cylindrical spacer", 1994 Annual Report - Conference on Electrical Insulation and Dielectric Phenomena, IEEE Publication 94CH3456-1, pp. 167-176, 1994

[10] T. O. Rerup, G. C. Crichton and I. W. McAllister, "The $\lambda$ function and the response of electrostatic probes", NORD-IS 94, Vaasa, pp.343-351, 1994

[11] T. O. Rerup, G. C. Crichton and I. W. McAllister, "The response of electrostatic probes via the $\lambda$ function", Conference Record of the 1994 IEEE International Symposium on Electrical Insulation, IEEE Publication 94CH3445-4, pp.82-88, 1994. 